\title{
Dento-Alveolar Distraction - Cutting Edge In Orthodontics
}

\author{
Dr. Abhidnya Madansure ${ }^{1}$, Dr. Suresh Kangane ${ }^{2}$, Dr. Anand Ambekar ${ }^{3}$, \\ Dr. Pravinkumar Marure ${ }^{4}$ \\ ${ }^{1,2,3,4}$ Maharashtra Institute of Dental Science and Research College, Latur,
}

\begin{abstract}
Most of the patients seeking orthodontic treatment have one wish that is Need for Speed. In order to reduce duration of orthodontic treatment, many methods have been introduced in the literature. One of the most recent technique is Dento-Alveolar Distraction-DAD technique.This article explains the concept of dentoalveolar distraction in rapid distalization of canine in orthodontic cases requiring first premolar extraction.
\end{abstract}

Keywords: Accelerating orthodontics, dentoalveolar distraction, distraction Osteogenesis

\section{Introduction}

One of the factor in the wish list of Orthodontic patients, especially in adult orthodontic patient is the 'Need For Speed'. Although nonextraction treatment has become popular and is preferred by many orthodontists, patients with severe malocclusion inevitably need extractions. ${ }^{1}$ The phase of canine retraction in extraction cases itself lasts for about 6-8 months. Thus completion of orthodontic treatment requires a long duration of about 2-3 years, ${ }^{2}$ which is a great concern in terms of caries, ${ }^{3}$ external root resorption, ${ }^{4}$ and decreased patient compliance. ${ }^{5}$

Conventional orthodontics rely on biological tooth movements, due to which tooth movement can be achieved at a limited rate. ${ }^{6,7}$ Several innovative techniques have been reported to accelerate orthodontic tooth movement, till the date, including (1) Low-level laser therapy- mechanical activation combined with LLLT increases the rate of tooth movement. ${ }^{8}$ (2) Pulsed electromagnetic fields- With exposure to a PEMF, canine retraction rate was increased by $1.57 \pm 0.83 \mathrm{~mm}^{9}$ (3) electrical currents- exogenous electric current from the miniature electric device might accelerate orthodontic tooth movement by one third and have the potential to reduce orthodontic treatment duration. ${ }^{10}$ (4) Corticotomy- Corticotomy is defined as any intentional surgical injury to cortical bone. The increased rate of tooth movement after corticotomy-facilitated orthodontics (CFO) is attributed to a "regional acceleratory phenomenon" (RAP), which is characterized by an increase in bone turnover and a drop in mineral content. ${ }^{11}$ (5) Mechanical vibration. - Application of resonance vibration might accelerate orthodontic tooth movement via enhanced RANKL expression in the periodontal ligament without additional damage to periodontal tissues such as root resorption. ${ }^{12}$ and (6) distraction osteogenesis. - Distraction osteogenesis is a process whereby new bone is grown by mechanically stretching a pre-existing bone tissue. ${ }^{13}$

\section{History}

Alessandro Codivilla In early 20th century introduced a method of distraction osteogenesis for lengthening of the lower limbs. ${ }^{14}$ However, at that time, it did not gain immediate acceptance until Gavril Ilizarov 1969, developed a technique for repairing complex fractures or nonunion of the long bones. Over the years, the technique was perfected, stimulating interest in distraction osteogenesis. ${ }^{15}$ Guerrero $^{16}$ in 1990 and MaCarthy et $\mathrm{al}^{17}$ in 1992 performed distraction osteogenesis in human mandible. Since then it has been applied to various bones of craniofacial skeleton. In 1998, Liou and Huang introduced the concept of distraction osteogenesis in tooth movement in the form of periodontal ligament osteogenesis. They stated that the process during tooth movement induced by orthodontic forces is similar to that of the midpalatal suture during rapid palatal expansion performed for crossbite correction. This technique has been named dental distraction (DD). ${ }^{18}$

Later in 2002, Kisnisci et al introduced dentoalveolar distraction, which is a surgical approach based on osteotomies around the teeth, to move the segment of bone containing the canines distally ${ }^{19}$. Iseri et al used this approach to move canines distally $1 \mathrm{~mm}$ per day in 8 to 14 days. Because it relies on distraction osteogenesis, dentoalveolar distraction has greater expectations to hold greater potential for generating bone than periodontal distraction $^{20}$. This is because surgical technique does not rely on the stretching and widening of the periodontal ligament, thus prevents overloading and stress accumulation in the periodontal tissues. Since then many case reports have been published regarding the use of Dentoalveolar Distraction Technique. 
Histology

In Dentoalveolar distraction, gradual and controlled displacement of a bone segment can be obtained with the use of force vectors in desired directions without extensive surgical interventions. ${ }^{21}$ histologically, distraction shows 3 fundamental sequential phases ${ }^{22}$.

1. The latency phase - the period between the surgical osteotomy and the beginning of traction, during which soft callus is formed. It is expressed between 0 and 7 days and coincides with the initial events of the normal bone repair process.

2. The distraction phase - slow and gradual traction force is applied to the transport bone segment, and the formation of new immature woven and parallel-fibered bone commences. This phase usually lasts 1 to 2 weeks, and the traction modifies the normal development of the regeneration process.

3. The consolidation phase begins after the desired correction has been achieved; this period allows for maturation of the regenerate and corticalization of the newly formed bone. ${ }^{23}$

\section{Indications Of Dad $^{20}$}

1. Patients with compliance problems (for social and pro $\neg$ fessional reasons)

2. Older adolescent and adult patients with moderate or severe crowding

3. Adult Class II, Division 1 patients

4. Bimaxillary dental protrusion patients

5. Orthognathic surgery patients needing dental decompensation

6. Patients with root shape malformations, short roots, and periodontal problems

7. Patients with ankylosed teeth

\section{Method Of Distractor Construction}

A custom-made, rigid, tooth-borne, intraoral distraction device can be designed and used in the DAD patients. The device is made up of stainless steel with one distraction screw, two guidance bars, and a screw to activate the distractor by turning the screw clockwise. The distractor can be fabricated from a conventional Hyrax expander. ${ }^{24}$ (Fig 1) ${ }^{25}$. The Hyrax should be opened according to the number of millimetres that canines has to be distalized, plus at $2 \mathrm{~mm}$. preferably, a $13 \mathrm{~mm}$ screw should be used. Bands are fabricated for the canines and first molars, and a transfer impression is made to allow the welding of the distractor to the bands once these have been positioned on the working model. One of the rods of the Hyrax is trimmed off and the sharp edges are then rounded off (Fig 2) ${ }^{25}$. Proper polishing is necessary, in order to ensure greater patient comfort. The original arrow on the screw should be pointing towards occlusal to facilitate activation and prevent forces from moving the distractor during the activation process. (Fig 3,4) ${ }^{26}$ Thus, as activations will be made in the opposite direction of the arrow, it decreases the likelihood that the device be displaced. The distractor can be then cemented but make sure that the screw is completely closed and opened.
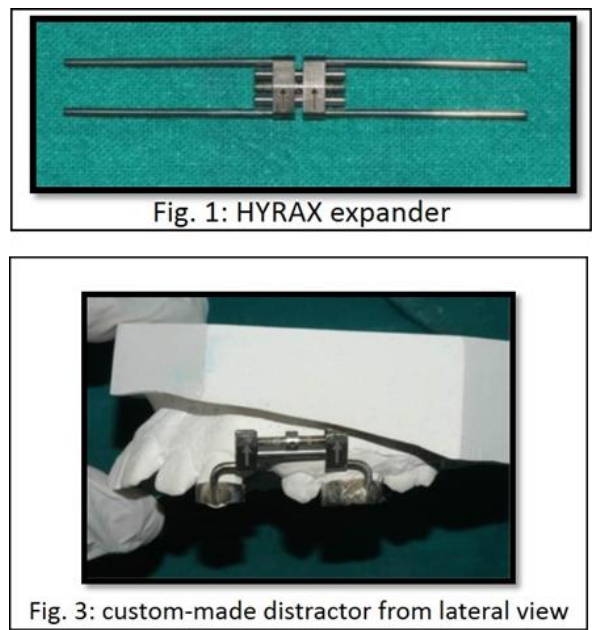
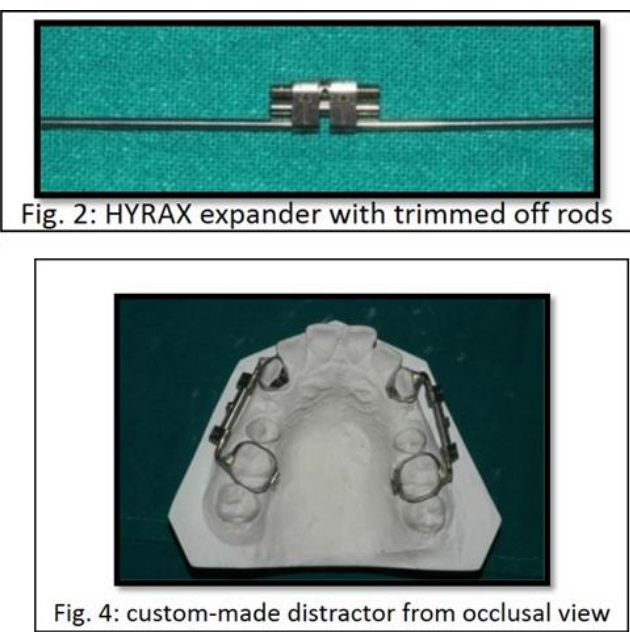

III. Modifications Of Distractor

Palatal distractor: Made from a Hyrax screw without any clipping. Just turning it 90 degrees allows it to be used for retraction (Fig 5) ${ }^{27}$. Recommended for cases where the two canines are initially proclined as it enables moving both teeth into the alveolar process. 
Unilateral palatal distractor: Identical to the device advocated by Faber and described above, but positioned via the palate. Suitable for canines in any position when the goal is to prevent buccal inclination (Fig 6). 27
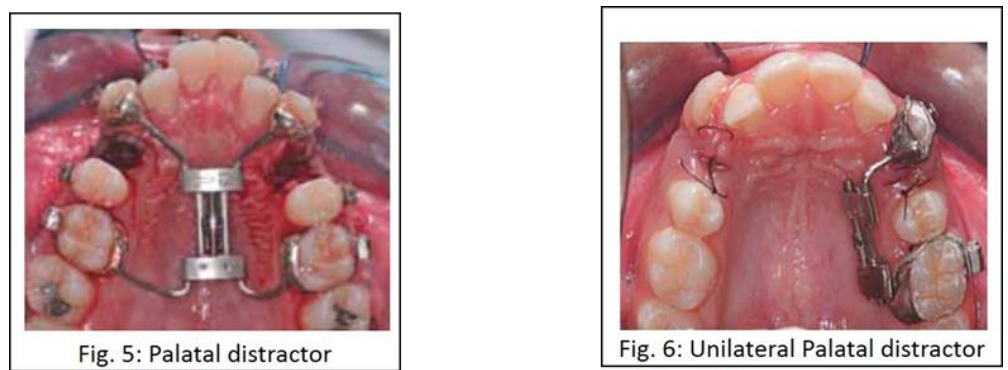

\section{Surgical Technique}

The surgical procedure was described by Kisnisci et al. which is usually performed on an outpatient basis, with the patient under local anaesthesia, many a times supplemented with sedation. Horizontal mucosal incision was made parallel to the gingival margin of the canine and the premolar beyond the depth of the vestibule.

Cortical holes are made in the alveolar bone with a small, round, carbide from the apex. A thin, tapered, fissure bur can be used to connect the holes around the root. Fine osteotomes are advanced in the coronal direction. The first premolar is then extracted and the buccal bone is removed between the outlined bone cut at the distal canine region anteriorly and the second premolar posteriorly. Larger osteotomes are used to fully mobilize the alveolar segment that included the canine by fracturing the surrounding spongious bone around its root off the lingual or palatal cortex. The buccal and apical bone through the extraction socket and the possible bony interferences at the buccal aspect that might be encountered during the distraction process should be eliminated or smoothed between the canine and the second premolar, preserving palatal or lingual cortical shelves. The palatal shelf should be preserved, but the apical bone near the sinus wall has to be removed, leaving the sinus membrane intact to avoid interferences during the active distraction process. Osteotomes along the anterior aspect of the canine are used to split the surrounding bone around its root from the palatal or lingual cortex and neighbouring teeth. The transport dentoalveolar segment that includes the canine also includes the buccal cortex and the underlying spongy bone that envelopes the canine root, leaving an intact lingual or palatal cortical plate and the bone around the apex of the canine.

The incision should be closed with absorbable sutures, and an antibiotic and a nonsteroidal antiinflammatory drug should be prescribed for 5 days. The surgical procedure lasted approximately 30 minutes for each canine. ${ }^{20}$ (fig. 7$)^{26}$

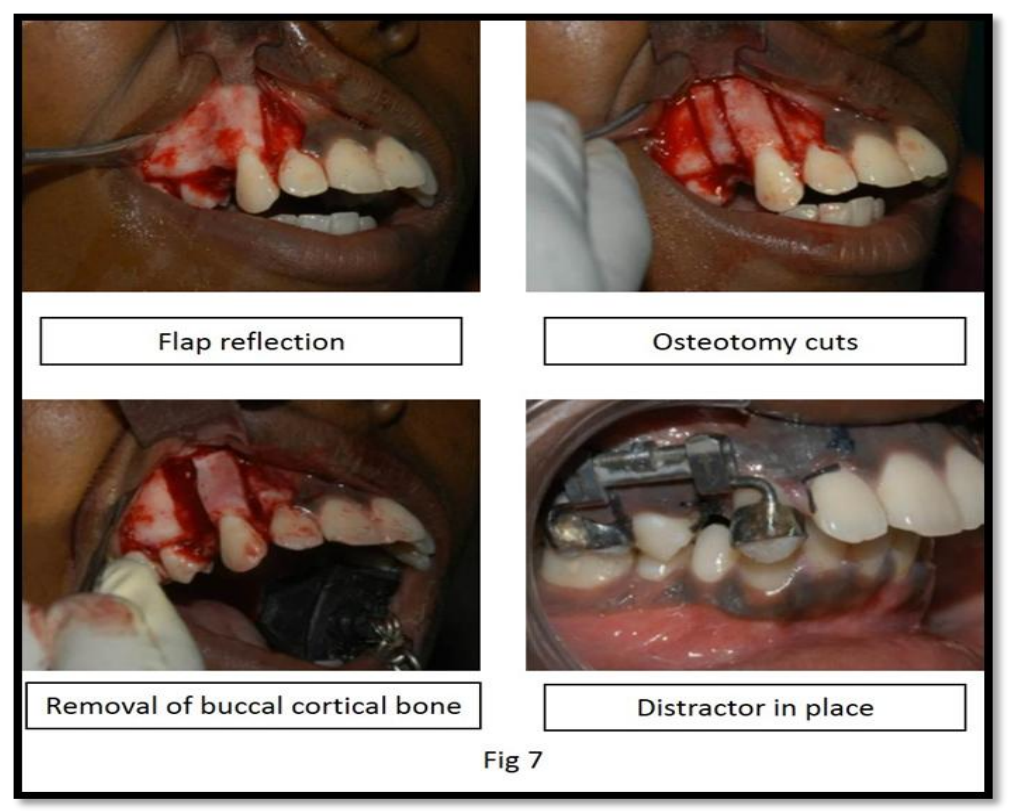




\section{Activation Protocol}

Distraction can be 3 days after surgery. Kisnisci has advised to activate the distractor twice per day, in the morning and in the evening, for a total of $0.8 \mathrm{~mm}$ per day. After the canine retraction is completed, fixed orthodontic appliance treatment should be initiated, it is also advised that the distracted canine and the first molar should be consolidate and kept at least 3 months after the DAD procedure. ${ }^{20}$

\section{Discussion}

The concept of distraction osteogenesis has been used for the purpose of canine retraction in order to achieve rapid tooth movement. But this technique where the canine is moved along with its dentoalveolar segment is an innovative and brings about faster tooth movement. In conventional orthodontics, when distally directed forces are applied on the canine it shows hyalinization phase which lasts for about $2-3$ weeks ${ }^{28}$ and tooth movement continues at a rate of 1 to $1.5 \mathrm{~mm}$ in 4 to 5 weeks. ${ }^{29} \mathrm{On}$ the other hand, with the custom-made, rigid, tooth-borne distractor, canine retraction occurred at a rate of $0.8 \mathrm{~mm}$ per day. Complete canine retraction was possible within 8 to 14 days. This is the most rapid movement of a tooth demonstrated in the literature. Two guidance bars of the distractor provide translation movement but slight tipping in the socket is observed. Anchorage loss is clinically insignificant as the duration of canine retraction is very short for movement of molar. The mean sagittal and vertical anchorage losses were $0.19 \mathrm{~mm}$ and $0.51 \mathrm{~mm}$, respectively, during rapid insignificant amount of extrusion of the distraction of the canines. ${ }^{20}$ Insignificant extrusion of maxillary first molars $(0.51 \pm 0.93 \mathrm{~mm})$. Hence, vertical anchorage loss of the maxillary first molars, especially in patients with open bite or tendency to open bite should be considered using DAD technique. Root resorption is usually associated cases with prolonged treatment duration. ${ }^{30}$ root resorption begins 2 to 3 weeks after the orthodontic force is applied. ${ }^{31}$ Full retraction of the canines with DAD completes in 8 to 14 days which is an extremely short time for root resorption to begin. Other than root resorption, No clinical and radiographic evidence of complications, such as root fracture, root resorption, ankylosis, and soft tissue dehiscence, was observed. ${ }^{20}$

Pulp vitality was evaluated and recorded with an electronic digital pulp tester and a thermal pulp tester. ${ }^{20}$ The pulp-vitality test is not a reliable technique when performed during orthodontic tooth movement. ${ }^{18}$ Thus, further investigation of pulp vitality is needed in patients subjected to rapid tooth movement with dentoalveolar distraction.

\section{Conclusion}

Tooth movement occurs due to biological changes that occur when tooth is subjected to the orthodontic force. Faster tooth movement will not arise only from bracket or wires but from altering biology. Osteotomies or corticotomies create injuries in the bone via fractures, causing a change in the metabolism leading to the regional accelerating phenomenon (RAP), including increase in osteoclasts, osteoblasts, mediators, and cell precursors of the blood and lymph vessels in the injured area, which positively promote the speed of orthodontic movement. Dentoalveolar distraction technique alters the biology and brings about rapid tooth movement. With dentoalveolar distraction, canines can be fully retracted in 8-14 days. This technique is known to reduce orthodontic treatment duration by 6 to 9 months in patients who need extraction, with no need for any sort of anchorage reinforcement. Thus increases patient's compliance. Teeth with anatomic malformations, periodontal problems, or ankylosed teeth will benefit from this technique. With this technique, molars can withstand the retraction forces better with no anchorage loss, and without clinical or radiographic evidence of complications such as root resorption, ankylosis, periodontal problems, and soft tissue dehiscence. Along with the canine retraction, dentoalveolar distraction technique can be implied in the cases of ankylosed teeth, molar intrusion, and maxillary expansion and seems to be the forefront of accelerated orthodontics.

\section{References}

[1]. Vig P, Weintraub JA, Brown C, Kowalski CJ. Duration of orthodontic treatment with and without extractions. Am J Orthod Dentofacial Orthop 1990;97:45-51.

[2]. Fink DF, Smith RJ. The duration of orthodontic treatment. Am J Orthod Dentofacial Orthop. 1992;102:45-51.3. Geiger AM, Gorelick L, Gwinnett AJ, Benson BJ. Reducing white spot lesions in orthodontic populations with fluoride rinsing. Am J Orthod Dentofacial Orthop. 1992; 101:403-407.

[3]. Segal GR, Schiffman PH, Tuncay OC. Meta analysis of the treatment-related factors of external apical root resorption. Orthod Craniofac Res. 2004;7:71-78.

[4]. Royko A, Denes Z, Razouk G. The relationship between the length of orthodontic treatment and patient compliance. Fogorv Sz. 1999;92:79-86.

[5]. Proffit WR, Fields HW: Fixed and removable appliances, in Proffit WR, Fields HW (eds): Contemporary Orthodontics (ed 2). St Louis, MO, Mosby-Year Book, 1993, pp 317-373

[6]. Reitan K: Biomechanical principles and reactions, in Graber TM, Swain BF (eds): Orthodontics: Current Principles and Techniques. St Louis, MO, CV Mosby, 1985, pp 101-192

[7]. Cruz DR, Kohara EK, Ribeiro MS, Wetter NU. Effects of lowintensity laser therapy on the orthodontic movement velocity of human teeth: a preliminary study. Lasers Surg Med. 2004; 35:117-120. 
[8]. Showkatbakhsh R, Jamilian A, Showkatbakhsh M. The effect of pulsed electromagnetic fields on the acceleration of tooth movement. World J Orthod. 2010;11:e52-e56.

[9]. Kim DH, Park YG, Kang SG. The effects of electrical current from a micro-electrical device on tooth movement. Korean J Orthod. 2008;38:337-346.

[10]. Aboul-Ela SM, El-Beialy AR, El-Sayed KM, Selim EM, El- Mangoury NH, Mostafa YA. Miniscrew implant-supported maxillary canine retraction with and without corticotomyfacilitated orthodontics. Am J Orthod Dentofacial Orthop. 2011;139:252-259.

[11]. Nishimura M, Chiba M, Ohashi T, et al. Periodontal tissue activation by vibration: intermittent stimulation by resonance vibration accelerates experimental tooth movement in rats. Am J Orthod Dentofacial Orthop. 2008;133:572-583.

[12]. Annino DJ, Goguen LA, Karmody CS. Distraction Osteogenesis for reconstruction of mandibular symphyseal defect. Arch Otolaryngol Head Neck Surg 1994;120:911-6.

[13]. Codivilla A. On the means of lengthening, in the lower limbs, the muscles and tissue which are shortened through deformity. Am J Orthop Surg 1905;2:353.

[14]. Ilizarov GA. The tension-stress effect on the genesis and growth of tissues part I the influence of stability of fixation and soft tissue preservation. Clin Orthop Relat Res 1989;238:249-81.

[15]. Guerrero CA, Bell WH, Contasti GI, Rodriguez AM. Mandibular widening by intraoral distraction osteogenesis. Br J Oral Maxillofac Surg 1997;35(6):383-92.

[16]. McCarthy JG, Schreiber J, Karp N, Thorne CH, Grayson H. Lengthening the human mandible by gradual distraction. Plast Reconstr Surg 1992;89:1-10.

[17]. Liou EJ, Huang CS. Rapid canine retraction through distraction of the periodontal ligament. Am J Orthod Dentofacial Orthop. 1998 Oct;114(4):372-82.

[18]. Kisnisci RS, Iseri H, Tuz HH, Altug AT. Dentoalveolar distraction osteogenesis for rapid orthodontic canine retraction. J Oral Maxillofac Surg 2002;60:389-94.

[19]. Iseri H, Kisnisci R, Bzizi N, Tuz H. Rapid canine retraction and orthodontic treatment with dentoalveolar distraction osteogenesis. Am J Orthod Dentofacial Orthop 2005;127(5):33-41.

[20]. Fernandes FHCN, Orsi IA, Bezzon OL. Distraction osteogenesis in dentistry. Int J Morphol 2010;28:743-8.

[21]. Senşık NE, Koçer G, Kaya BÜ. Ankylosed maxillary incisor with severe root resorption treated with a single-tooth dento-osseous osteotomy, vertical alveolar distraction osteogenesis, and mini-implant anchorage. Am J Orthod Dentofacial Orthop 2014;146:371384.

[22]. Cohen SR, Rutrick RE, Burstein FD. Distraction osteogenesis of the human craniofacial skeleton: initial experience with new distraction system. J Craniofac Surg 1995;6:368-74.

[23]. Faber J. Pergunte a um expert. Rev Clín Ortod Dental Press. 2005 ago-set;4(4):12-21.

[24]. Shashidhara KK. A Comparative Study of Canine Retraction by Distraction of the Periodontal Ligament and Dentoalveolar Distraction Methods. J. Maxillofac. Oral Surg. 2016; 15(2):144-155

[25]. Kumar N, Prashantha GS, Raikar S, Ranganath K, Mathew S, Nambiar S. Dento-Alveolar Distraction Osteogenesis for rapid Orthodontic Canine Retraction. J Int Oral Health 2013; 5(6):31-41.

[26]. Ribeiro PRC, Fernandes SHC, Oliveira GS Rapid canine retraction. Dental Press J. Orthod. [Internet].2016;16( 1 ): 13-157.

[27]. Reitan K. Initial tissue behaviour during apical root resorption. Angle Orthod 1974;44:68-82.

[28]. Pilon JJGM, Kuijpersa-Jagtman AM, Maltha JC. Magnitude of orthodontic forces and rate of bodily tooth movement, an experimental study in beagle dogs. Am J Orthod Dentofacial Orthop 1996;110:16-23.

[29]. Reitan K. Tissue behavior during orthodontic tooth movement. Am J Orthod 1960;46:881-900.

[30]. Kurol J, Owman-Moll P, Lundgren D. Time-related root resorption after application of a controlled continuous orthodontic force. Am J Orthod Dentofacial Orthop 1996;110:3 